\title{
Preschool meals as a source of nutrients for 3-6-year-old Finnish preschoolers
}

\author{
$\underline{\text { Kaija Nissinen }}^{1,2}$, Liisa Korkalo ${ }^{2}$, Henna Vepsäläinen ${ }^{2}$, Essi Skaffari ${ }^{2}$ Reetta Lehto ${ }^{3}$, \\ Leena Koivusilta ${ }^{4}$, Eva Roos ${ }^{3}$ and Maijaliisa Erkkola ${ }^{2}$ \\ ${ }^{1}$ School of Food and Agriculture, Seinäjoki University of Applied Sciences, Seinäjoki, Finland, \\ ${ }^{2}$ Department of Food and Nutrition, University of Helsinki, Helsinki, Finland, \\ ${ }^{3}$ Folkhälsan Research Center, Helsinki, Finland and \\ ${ }^{4}$ Department of Social Research, University of Turku, Turku, Finland
}

\begin{abstract}
Preschool meals influence the child's growth, development and learning ability. According to the Finnish National Nutrition Council, preschool meals should cover two thirds of the daily energy requirements if the child attends to a full-time childcare. We investigated the contribution of preschool meals on a weekday's total energy and nutrient intake among Finnish preschoolers. A cross-sectional DAGIS Study was conducted in 2015-2016. Altogether 864 3- to 6-year-old children from 66 preschools participated. Parents and early educators kept 3-day food records for the child. To capture the seasonal variation in the diet, $24 \%$ of the families also kept an additional 2-day food record. To assess the nutritional contribution of preschool meals, we selected a sub-sample of children based on the criteria that they ate all three meals (breakfast, lunch, afternoon snack) at preschool. This yielded a sub-sample of 557 children, each contributing the data with 1 to 4 full preschool days. Data was analysed using two age groups: 3-4 years $(\mathrm{n}=324)$ and 5-6 years $(\mathrm{n}=233)$. Mean intake of nutrients from different preschool meals and population proportions were calculated. Mean energy intake at preschool was 3.0 $\pm 0.8 \mathrm{MJ}$ for 3-4-year-olds and 3.5 $\pm 0.9 \mathrm{MJ}$ for 6-7-year-olds contributing 54\% of the total daily energy intake in both age groups. At preschool, lunch was the main single source of energy, protein, and fat. It was also an important source of folate (27\% of the total daily intake in the younger and $29 \%$ in the older age group) and of fibre ( $25 \%$ of the total daily intake in both age groups). Most of the added sugar was consumed at home $(61 \%$ in the younger and $63 \%$ in the older age group). Most of the polyunsaturated fatty acid intake occurred at the preschool meals, mostly at lunch. Salt intake at preschool was high $(3.2 \pm 1.1 \mathrm{~g} /$ day and $3.6 \pm 1.2 \mathrm{~g} /$ day in the younger and older age group, respectively). Cereal products were the main sources of salt at preschool. Preschool meals did not cover two thirds of the daily energy as recommended but preschool food was an important source of fibre, polyunsaturated fatty acids, folate, and vitamin D but also of salt. Salt intake at preschool needs to be tackled by reducing salt in recipes and using low-sodium bread.
\end{abstract}

\section{Conflict of Interest}

Liisa Korkalo is a board member of the company TwoDads Ltd. Otherwise the authors declare that they have no conflict of interest. 